\title{
Anther Rubbing, a New Mechanism That Actively Promotes Selfing in Plants
}

\author{
Mohamed Abdelaziz, ${ }^{1,2, \star, \dagger}$ Mohammed Bakkali, ${ }^{1}$ José M. Gómez, ${ }^{3,4}$ Enrica Olivieri, ${ }^{1}$ \\ and Francisco Perfectti ${ }^{1,5} \dagger$
}

1. Departamento de Genética, Universidad de Granada, 18071 Granada, Spain; 2. Biological and Environmental Sciences, School of Natural Sciences, University of Stirling, Stirling FK9 4LA, United Kingdom; 3. Departamento de Ecología, Universidad de Granada, 18071 Granada, Spain; 4. Departamento de Ecología Funcional y Evolutiva, Estación Experimental de Zonas Áridas (EEZA-CSIC), 04120 Almería, Spain; 5. Unidad de Excelencia “Modeling Nature," Universidad de Granada, 18071 Granada, Spain

Submitted May 3, 2018; Accepted August 15, 2018; Electronically published November 14, 2018

Online enhancements: videos. Dryad data: https://doi.org/10.5061/dryad.sd1hf16.

AвSTRACT: Self-fertilization has recurrently evolved in plants, involving different strategies and traits and often loss of attractive functions, collectively known as the selfing syndrome. However, few traits that actively promote self-fertilization have been described. Here we describe a novel mechanism promoting self-fertilization in the Brassicaceae species Erysimum incanum. This mechanism, which we called "anther rubbing," consists of autonomous, repeated, and coordinated movements of the stamens over the stigma during flower opening. We have documented anther rubbing by time-lapse videos and experimentally show that it causes self-pollen deposition on stigmas and is sufficient to achieve maximal reproductive output in E. incanum. We predict that these movements should occur in species with limited inbreeding depression, and indeed we find that inbreeding depression in seed production is negligible in this species. While many studies have documented complex floral traits that promote outcrossing, the occurrence of anther rubbing demonstrates that plants can evolve elaborate and underappreciated adaptations to promote self-fertilization.

Keywords: Erysimum incanum, kinetogamy, plant movements, timelapse videos, controlled crossing experiment.

\section{Introduction}

Plants exhibit a great variety of reproductive strategies, including combinations of asexual and sexual reproduction. Darwin dedicated much of his attention to studying the mechanisms underlying reproduction in plants (Darwin 1876, 1877). He attributed the evolution of floral traits and mechanisms that promote selfing to reproductive assurance (Darwin

\footnotetext{
* Corresponding author; email: mabdelazizm@ugr.es.

$\dagger$ These authors contributed equally to this work. ORCIDs: Abdelaziz, http://orcid.org/0000-0003-0533-6817.
}

Am. Nat. 2019. Vol. 193, pp. 140-147. (C) 2018 by The University of Chicago. 0003-0147/2019/19301-58444\$15.00. All rights reserved. DOI: $10.1086 / 700875$
$1876,1877)$ and the evolution of those that promote crossfertilization to the avoidance of producing offspring that suffer inbreeding depression, which he showed in a large series of experiments can strongly decrease seed germination, plant survival to maturity, and fertility (Darwin 1876, 1877). It is now widely accepted that many floral traits are adaptations to outcrossing and efficient cross-fertilization, and many are under direct selection from pollinators (Harder and Johnson 2009). Traits such as flower colors, attractive scents, and flower shapes have contributed to the diversification of flowering plants (van der Niet and Peakall 2014). Other traits promoting outcrossing include self-incompatibility systems as well as spatial separation of anthers from stigmas (herkogamy) or separation of their maturation times (dichogamy). Many studies of outcrossing-related floral traits have been conducted, and they support the idea that evolution has favored cross-fertilization over self-fertilization (Barrett 2002); in addition, many hermaphrodite plants have developed mechanisms to avoid selfing and its detrimental effects through inbreeding depression (Jarne and Charlesworth 1993). However, the shift from cross-fertilization to selfing is a very frequent evolutionary transition (Igic and Busch 2013) and one of the best-known cases of convergent evolution (Slotte et al. 2013). It is therefore remarkable that the traits that promote selfing in plants have been regarded mainly as losses of traits after cross-fertilization is lost or as nonadaptive by-products that are permitted after such losses (Takebayashi and Delph 2000) and have received much less attention as possible adaptations to selfing (Lloyd and Schoen 1992).

In this study, we describe a novel self-pollination mechanism involving autonomous active movements of anthers to rub the stamens over the stigma of the same flower. This mechanism was discovered in the highly selfing plant Erysimum incanum (Brassicaceae), an annual species widely dis- 
tributed in the Iberian Peninsula and northwestern Africa (Nieto-Feliner 1993).

\section{Methods \\ The Plant}

Erysimum incanum is an annual monocarpic that is herb widely distributed in lowland forests to subalpine scrublands and plateaus (elevation, 200-2,100 m) of the Iberian Peninsula and northwestern Africa (Nieto-Feliner 1993). It has a markedly patchy distribution, with local populations of hundreds of individuals occupying only a few square meters. Plants overwinter as vegetative rosettes and start flowering at the beginning of spring. Plants can produce more than a hundred small yellow flowers grouped in up to five reproductive stalks. In line with their reduced size, E. incanum flowers produce tiny amounts of nectar (see below), and both of these characteristics explain the unattractiveness to pollinators (M.A., personal observations in different Iberian and African populations over several years).

\section{The Populations}

During July 2015, we collected seeds from three different populations of E. incanum: one Iberian (from the Sierra Nevada in Granada Province, southeast Spain) and two African (one from the Middle Atlas Mountains in Ifrane Province, north-central Morocco, and the other from the High Atlas Mountains in the Marrakesh-Tensift-El Haouz region, central Morocco). We collected seeds of at least 20 plants per population. In addition, during the flowering season of 2015, we measured the lengths of filaments and styles in one flower per plant in 100 E. incanum plants from the Middle Atlas Mountains and calculated their herkogamy values. The offspring of these plants were grown under greenhouse conditions and were used to measure nectar production, which was measured using calibrated $0.5-\mu \mathrm{L}$ micropipettes (Kearns and Inouye 1993) on one newly opened flower per plant in 30 different plants of E. incanum.

\section{Time-Lapse Videos and Photographic Documentation}

Time-lapse videos were produced to record the opening of the flowers. Macrophotographic images were taken every $30 \mathrm{~s}$ for 12 to $24 \mathrm{~h}$ using an intervalometer, Canon 500D or $1000 \mathrm{D}$ cameras, and different lenses, depending on the setup and specimen used. We used a Canon EF 100-mm f/2.8L Macro lens, a Sigma 50-mm f/1.4 DG lens coupled to the camera through a reverse-lens coupling ring, and a Canon EF-S 18-55-mm f/3.5-5.6 IS lens mounted in a photographic bellow. The camera was placed on a vertical focusing rail fixed to a photographic stand. Specimens were illuminated with white LED light. To detect the subtle movements during flower opening, photographs were transformed to high-definition time-lapse videos using the free software Mencoder and were finalized using Final Cut Pro X (Apple). Each second of the resulting time-lapse videos represents $12 \mathrm{~min}$ of real time. We recorded the flower openings of several E. incanum specimens as well as specimens of the following Brassicaceae species: Alyssum granatense, Arabidopsis thaliana, Capsella bursapastoris, Erysimum bastetanum, Erysimum repandum, Erysimum wilczekianum, and Moricandia moricandioides.

A digital camera (OMAX A3530U microscope digital camera) attached to a Nikon SMZ445 stereomicroscope was used to document anther dehiscence and the presence of mature pollen at the start of flower opening (fig. $1 C$ ) as well as the deposition of the pollen grains from the anthers rubbing on the stigma while the flower was still opening (fig. 1D). The pollen maturity was not directly assessed but was inferred by its effect on producing seeds.

\section{Breeding Experiments and Fitness Assessment}

In November 2015, we sowed a pool of 30 seeds from each of the three populations sampled previously (one Iberian and two African populations), and the resulting plants were moved into a greenhouse when they started to bloom (around 2 months later) in order to avoid contact with any potential pollinator. A total of 42 plants (15 plants belonging to the Iberian population, and 17 and 10 plants belonging to each of the African populations) were used for each of the following treatments: (i) emasculation before stamen movement (EbM), in which we emasculated the flowers before they started opening (when anthers are still immature; this treatment was carried out to exclude the existence of asexual reproduction in this species, such as apomixis [Asker and Jerling 1992]); (ii) emasculation after stamen movement (EaM), in which we emasculated the flowers just after stamen movement and rubbing of their anthers on the stigma stops (the goal of this treatment was to explore the effect of anther rubbing on reproductive output as well as to check the maturity of the pollen grains); (iii) autonomous selfing (AS), where we did not manipulate the flowers for using it as control; and (iv) forced selfing (FS), where we removed half of the anthers of a flower and hand-pollinated it with its own pollen in order to assess the ability of the plants to reach their maximum reproductive output. An extra treatment, outcrossing (OC), was carried out as control of maximum reproductive output in outcrossing conditions in order to evaluate the mating system of the species. For this, we emasculated flowers of plants from the population of the Middle Atlas range while they were still closed, adding pollen from different plants of the same population to the stigma of the emasculated flowers when these became receptive. Experimental flowers were la- 

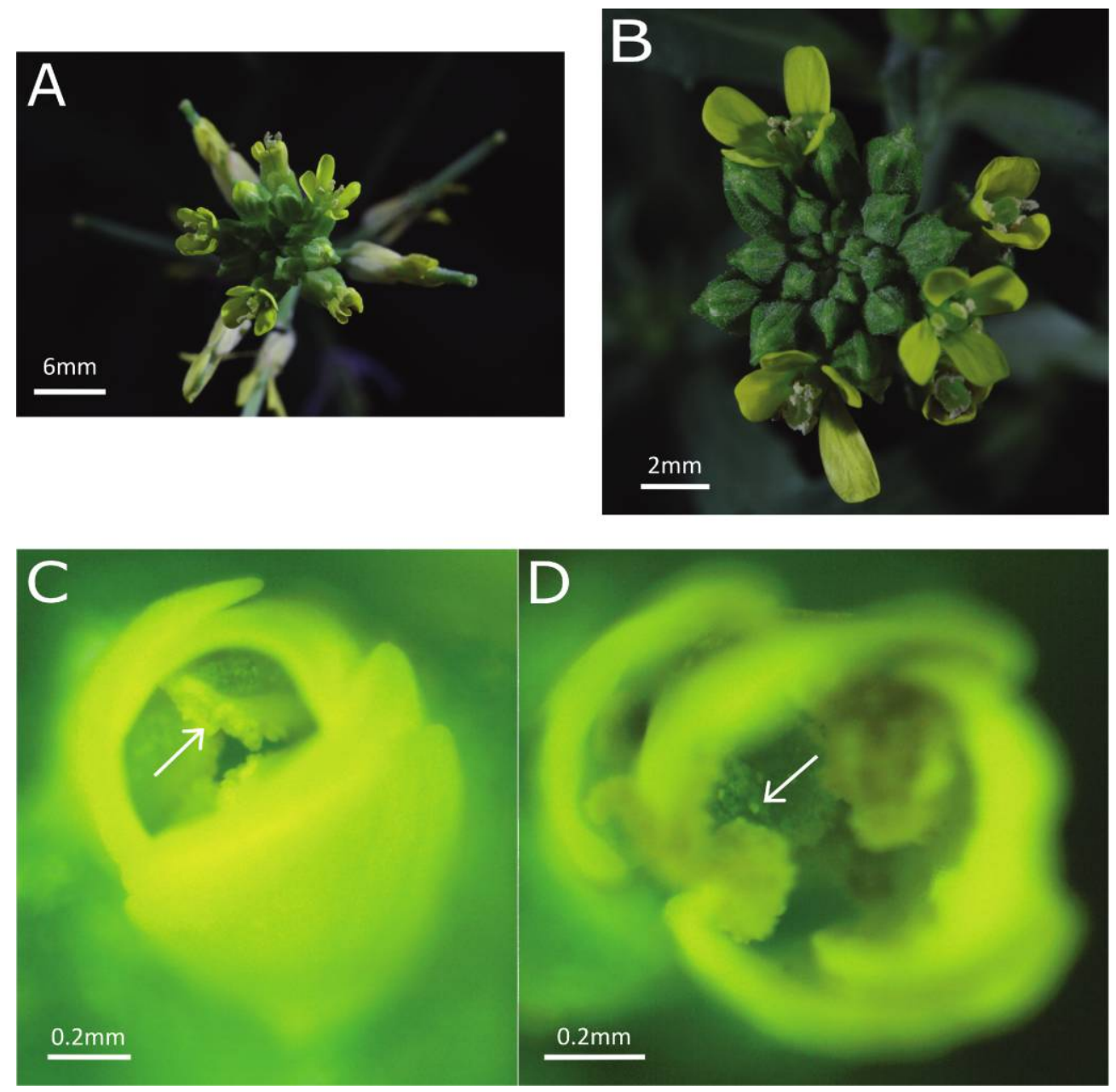

Figure 1: Erysimum incanum flowers. A, Macrophotography showing flowers during the opening period. Anthers are sited over the stigma, conferring reverse herkogamy. $B$, Anthers at different locations during anther rubbing. This species presents introrse anthers that open facing the below-located stigma at the center of the flower. $C$, Photograph showing open anthers and mature pollen at the beginning of the flower opening. The arrow shows the location of pollen aggregates on anthers. $D$, Presence of pollen grains on the stigma of the still-opening flower. The arrow indicates pollen aggregates on the stigma.

beled with different colored cotton threads depending on the treatment. At the end of the reproductive period, we calculated four quantities for each treatment and plant: (i) fruit set, the proportion of labeled flowers setting fruits; (ii) ovule fertilization (fertilization rate), calculated as the proportion of effectively fertilized ovules within a ripe fruit; (iii) fertility, the number of seed produced per fertilized ovule; and (iv) seed production, the number of seeds produced per total of ovules in a given fruit (data are available in the Dryad Digital Repository: https://doi.org/10.5061/dryad.sd1hf16 [Abdelaziz et al. 2018]).

Kruskall-Wallis tests for comparisons between treatments outputs were performed using the package stats in $\mathrm{R}$ ( $\mathrm{R}$ Development Core Team 2014). We also calculated an inbreeding depression index for the forced selfing and outcrossing treatments as $w_{\mathrm{x}} / w_{\mathrm{s}}-1$, where $w_{\mathrm{S}}$ and $w_{\mathrm{x}}$ are the mean numbers of fruits produced per self-fertilized and outcrossed flowers, respectively, or the mean number of seeds produced per fertilized ovule under selfing and outcrossing, respectively (Ågren and Schemske 1993).

\section{Results}

In Erysimum incanum, the anthers are face inward (introrse) and open facing the stigma, which is in the center of the flower, $0.83 \pm 0.63 \mathrm{~mm}$ below the anthers (fig. $1 \mathrm{~A}, 1 \mathrm{~B}$ ), a situation called reverse herkogamy (Webb and Lloyd 1986). When the flowers open, the stamens display slow, repeated swirling movements that last 240-280 min (video A1; videos A1-A3 are available online). Opposing anthers in a pair alternate 
rubbing against the stigma or directly against each other, depending on the relative length of the style (fig. $2 A, 2 B$ ). We confirmed using microphotographs that the moving anthers were mature and had viable pollen when they started to rub against each other or against the stigma (fig. $1 C$ ). We observed that the anther rubbing resulted in deposition of pollen grains on the stigma even when the stigma was not in contact with the anthers (fig. 1D). Therefore, anther rubbing is a mechanism that allows self-deposition of pollen grains.

To test the reproductive consequences of anther rubbing, we subjected the flowers of E. incanum to several experimental treatments. Removing the anthers from virgin flowers before the anther rubbing started (EbM treatment) abolished fertilization of the ovules, and no fruits or seeds were produced (fig. 3 ). This suggests that E. incanum has no asexual mechanisms of seed production, such as apomixis (Asker and Jerling 1992). When the anthers were removed after the rubbing (EaM treatment), the flowers pro- duced the same amount of fruits and seeds as did flowers left intact for their entire life span (AS treatment) or flowers that were hand-pollinated with their own pollen (FS treatment; fig. 3). We found no significant differences (KruskalWallis tests; fig. 3) between the four treatments producing fruits (EaM, AS, FSm, and OC) for fruit set, calculated as the number of fruits produced per flower $\left(\chi^{2}=0.49\right.$, $\mathrm{df}=3, P>.05)$; fertilization rate, calculated as the proportion of effectively fertilized ovules within a ripe fruit $\left(\chi^{2}=0.67, \mathrm{df}=3, P>.05\right)$; fertility, calculated as the number of seed produced per fertilized ovule $\left(\chi^{2}=0.19\right.$, $\mathrm{df}=3, P>.05)$; and seed set, calculated as the number of seeds produced per total of ovules in a given fruit $\left(\chi^{2}=0.60, \mathrm{df}=3, P>.05\right)$. Overall, our results indicate that the rubbing is sufficient for seed production.

Interestingly, E. incanum experienced no inbreeding depression in seed set. The reproductive success of AS flowers did not differ significantly from that of flowers hand-pollinated

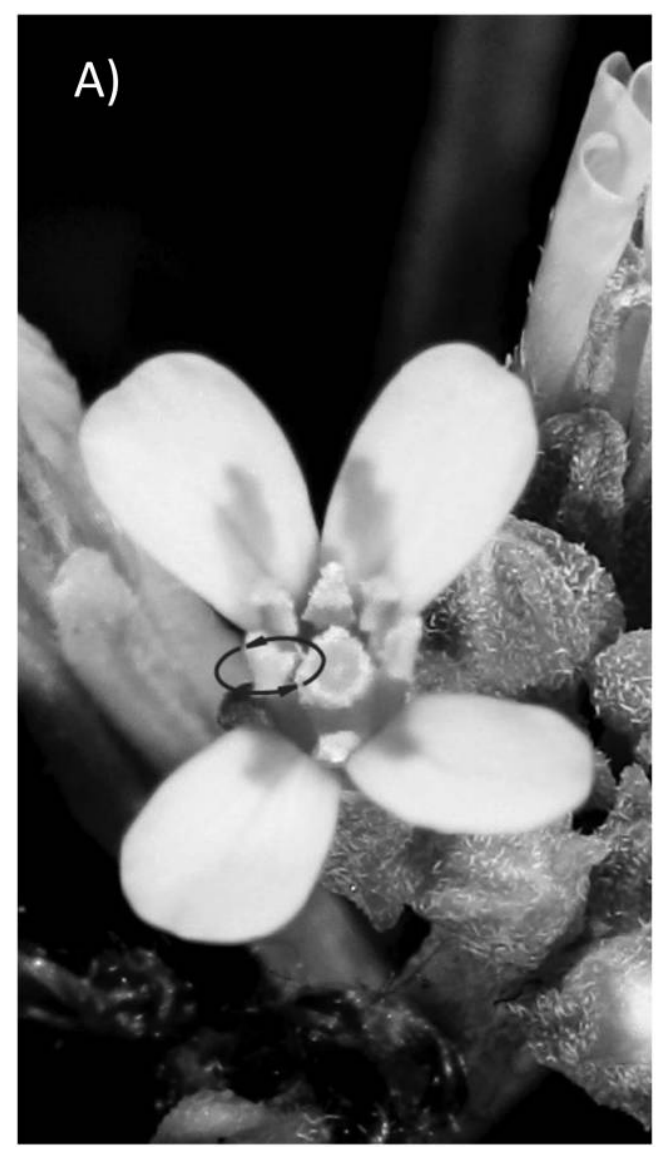

B)

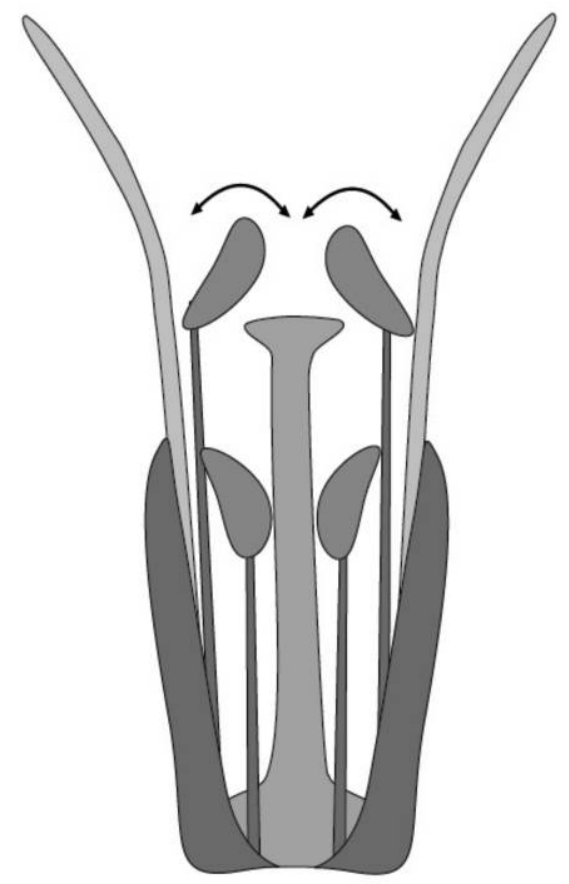

Figure 2: Erysimum incanum flower diagram and anther rubbing movement. A, Arrows show the movement described by anthers during anther rubbing. $B$, Lateral view for the specific locations of stigmas and anthers in the flowers. The arrows indicate the movement of the anthers during rubbing. 

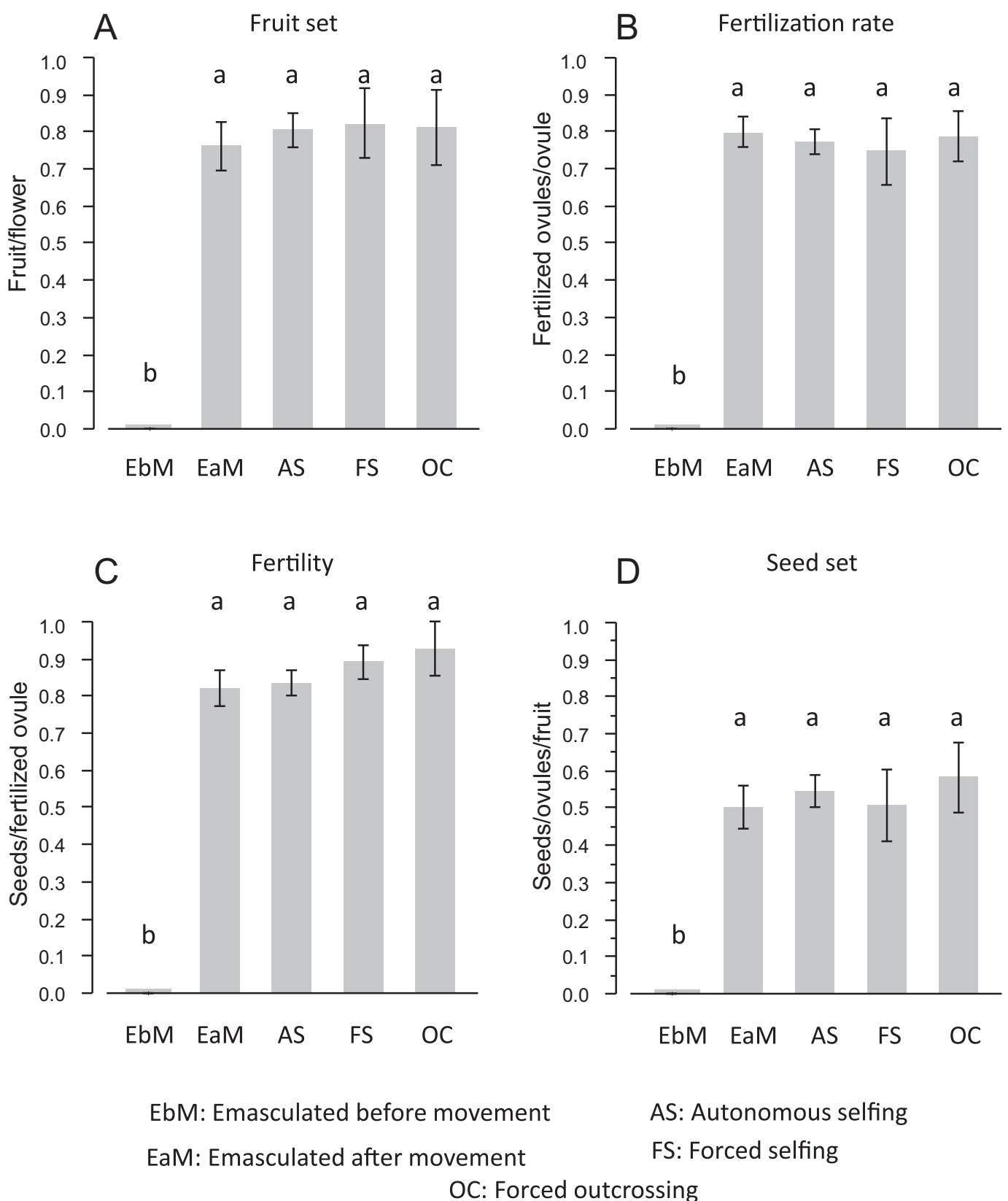

Figure 3: Reproductive output components estimated for each of the five breeding treatments. Mean values and standard error for each component are depicted. The values for flowers emasculated before movement (EbM) are zero because no flowers under this treatment produced any fruits or seeds. $A$, Fruit set, the proportion of labeled flowers setting fruits. $B$, Fertilization rate, calculated as the proportion of effectively fertilized ovules within a ripe fruit. $C$, Fertility, calculated as the number of seeds produced per fertilized ovule. $D$, Seed set, calculated as the number of seeds produced per total of ovules in a given fruit. No significant differences were detected between the emasculated after movement (EaM), autonomous selfing (AS), facilitated selfing (FS), and outcrossing (OC) treatments. Distributions not statistically significantly different by the paired Kruskal-Wallis comparison have the same letter.

with outcrossed pollen (OC treatment, where anthers were removed before the rubbing and the stigma was loaded with pollen from a different plant of the same population; fig. 3). Quantitatively, inbreeding depression was -0.04 for fruit set and -0.02 for the number of seeds per ovule.

\section{Discussion}

Erysimum incanum exhibits the typical phenotypic characteristics of a selfer: an annual life cycle (Nieto-Feliner 1993), low pollen-to-ovule ratio (Feliner 1991) within values typical 
for selfers (Cruden 1977), small flowers (petal size, 2.5-6 mm; Nieto-Feliner 1993), one of the smallest flower sizes among all Erysimum species (Feliner 1991), very low nectar production $(0.012 \pm 0.003 \mu \mathrm{L}$ of nectar per flower), and absence of pollinator visitors (M.A., personal observation based on more than 40 cumulative hours of monitoring several natural populations). In addition, the cost of autogamy in E. incanum measured in seed or fruit production is small. This contrasts with what has been observed in delayed autonomous self-fertilization, where autogamy contributes only partially to fruit production (Nagy et al. 1999). Moreover, the reproductive success of EbM flowers was significantly lower than that of the other treatments (fig. 3), suggesting that anther rubbing is sufficient for the plant to reach maximal reproductive output. Erysimum incanum thus appears to be fully adapted to autogamous reproduction. However, we cannot rule out the existence of low levels of outcrossing in E. incanum populations. In fact, low levels of outcrossing have been found in other predominantly selfing species, such as Arabidopsis thaliana (Abbott and Gomes 1989; Bomblies et al. 2010), and theoretical work on low levels of outcrossing in predominant selfers has recently shown that it can be adaptive (Kamran-Disfani and Agrawal 2014).

Anther rubbing does not occur in the related species Erysimum wilczekianum, Erysimum bastetanum, and Erysimum repandum (video A2), suggesting that this mechanism evolved in the E. incanum lineage. Just like the other Erysimum species, none of the other Brassicaceae species analyzed here (Alyssum granatense, A. thaliana, Capsella bursa-pastoris, and Moricandia moricandioides) showed anther rubbing (video A3). However, time-lapse videos show that the mature anthers of the autogamous $A$. thaliana and A. granatense appear to approach the stigma during flower closure (video A3), suggesting that some self-pollination may occur during flower closure in these species. It will be interesting in the future to test whether these movements are related to anther rubbing or are different phenomena also favoring fertilization.

Developmental movements of floral parts, such as flower closure, may also promote self-fertilization. However, anther rubbing is qualitatively distinct from movements in floral parts as flowers close because it results in effective prior selfreproduction (before pollinator visits and outcrossing opportunities), although not necessarily precluding some outcrossing. In comparison to competing fertilization during pollinator visits (Lloyd 1979) or delayed self-fertilization when pollinators have failed to visit (Sakai 1995), the reproductive assurance hypothesis (Darwin 1876) predicts that prior selffertilization should be advantageous when pollinators are scarce, when populations have purged alleles that produce inbreeding depression (Kalisz et al. 2004), and when a high reproductive output is vitally advantageous - that is, when plants compete for fast reproduction (Wolkovich and Cleland 2011).
Lloyd (1992) showed that among all possible autonomous self-pollination modes, prior selfing is the type associated with limited or no inbreeding depression. In agreement with this idea, E. incanum appears to have low levels of inbreeding depression. Nevertheless, other life stages beyond seed set and other populations should be explored to accurately determine the level of inbreeding depression in E. incanum, since it has been shown that inbreeding depression can be also strong in postdispersal stages (Husband and Schemske 1996; Angeloni et al. 2011) and can vary among populations (Whitehead et al. 2018). Considering that many angiosperms are highly selfing (ranging from up to approximately $20 \%$ proposed by Barrett [2002] to $13 \%$ proposed by Ollerton et al. [2011]), anther rubbing and related phenomena may have evolved in other species with an apparent similar lack of inbreeding depression, possibly under conditions of pollinator limitation.

The conditions for the evolution of mechanisms producing prior selfing are more stringent than for other types of selfing, such as delayed selfing (Lloyd 1992). Usually they include outcrossing pollen limitation mainly caused by scarcity of pollinators and absence of self-incompatibility mechanisms. When there is a short interval between self-pollen deposition and the possibility of deposition of outcrossingpollen, pollen prepotency (i.e., the very high success of outcrossing pollen in competition with self-pollen) could provide some degree of outcrossing, and prior selfing would be as advantageous as delayed selfing (Lloyd 1992). But when the probability of ovules being fecundated by outcrossing pollen is very low, seed discounting (i.e., the reduction in crossfertilized seeds produced by an increase in the amount of selffertilized seeds; Lloyd 1992) will be very low, producing the conditions for prior selfing to evolve (Lloyd 1992). In addition, a recent study has show how, in a scenario of interspecific pollinator sharing, prior selfing could reduce the costs associated with the deposition of heterospecific pollen (Randle et al. 2018). In that scenario, the evolution of traits such as anther rubbing could be also selected.

Movements have long been studied in plants, for example, flowers tracking the sun and rapid leaf folding or dropping (Ruan and da Silva 2011). Darwin recorded plant movements in his pioneering work on nutation and other movements in insectivorous and climbing plants (Darwin and Darwin 1880; for a depiction of Darwin's setup, see Edwards and Moles 2009). Movements of stamens or pistils have previously been described in other plant species, but they often rely on the actions of other species, typically serving in the transfer of pollen to pollinators (Müller 1883). Some plants show haptonastic movements, that is, in response to touch stimuli, usually triggered by pollinators, as when the stamens of Portulaca grandiflora bend when contacted by pollinators (Jaffe et al. 1977) or the mechanically stimulated stamens of Opuntia viridubra move inward to the center of the flower in 
order to hide pollen from inefficient pollinators, thus favoring bees (Schlindwein and Wittmann 1997). Stamens can also move and increase the accuracy of pollen transfer to pollinators, as in Parnasia epunctulata (Armbruster et al. 2014) and Ruta graveolens; in the latter species, stamen movement at the end of the anthesis appears to result in delayed selfpollination (Ren and Tang 2012) rather than outcrossing. Movements involved in delayed self-pollination have also been recorded. For instance, the stipe supporting the anthers of the orchid Holcoglossum amesianum can undergo an antigravity $360^{\circ}$ turn that allows insertion of the pollen into the stigmatic cavity (Liu et al. 2006). Similarly, facultative selfpollination occurs in unpollinated Hibiscus trionum when stylar branches curve down and contact anthers of the flowers that have not been visited by pollinators - deposition of pollen on the stigma arrests these movements (Buttrose et al. 1977). In contrast to these and the other known cases, the anther rubbing described here is a wholly autonomous movement producing prior selfing.

The recording of floral movement has long attracted attention. In 1903, Scott (1903) recorded the movements of Sparrmannia africana flowers with a kinematograph using a technique conceptually similar to the modern time lapses we have used here. The equipment needed for recording time-lapse videos is affordable, opening the possibility of exploring anther rubbing and similar underappreciated movements in other plant species. We propose the term "kinetogamy" to cover plant reproduction mechanisms that involve any autonomous, active, and coordinated movement of any part of the flower. The term excludes any type of accidental or by-product movements that might take place in a flower and promote its fertilization (e.g., contacts between stigma and stamens produced, as a by-product, during flower opening or closure; movement of flower parts due to the action of rain or wind; or any other accidental displacement of the reproductive organs).

Conclusions. The current work presents anther rubbing as a newly discovered mechanism that promotes selfpollination in a plant due to active and repeated movements of their stamens. Its consequence, in terms of effective pollen deposition on the stigma, allows E. incanum plants to autofertilize. Anther rubbing thus stands as a proper and novel trait that contributes to the selfing syndrome so prevalent in many plants (Sicard and Lenhard 2011). We think other cases of anther rubbing may be discovered in the future, once biologists start looking for such behaviors.

\section{Acknowledgments}

We are grateful to Juan Arroyo, $\mathrm{M}^{\mathrm{a}}$ Clara Castellanos, Deborah Charlesworth, Jeff Conner, Alistair Jump, Marcos Méndez, A. Jesús Muñoz-Pajares, Luis Navarro, Jeff Ollerton, Carolina Osuna, John Pannell, Xavier Picó, Isabel Reche,
Carl Rothfels, Mark Schwartz, Sharon Strauss, and Pablo Vargas for discussion and comments. Modesto Berbel and Xavier Picó provided Arabidopsis thaliana, and Adela González-Megías provided plants of Moricandia moricandioides. We thank Abdeselam Mohamed Maanan for his support and help locating and sampling natural populations. Grants from the Spanish Ministerio de Economia y Competitividad (CGL2013-47558-P, CGL2014-59886-JIN, and CGL201786626-C2-2-P), including Fondo Europeo de Desarrollo Regional-European Commission (EU-FEDER) funds, supported this study. M.A. has been supported by an Impact Research Fellowship from the University of Stirling and the TransSpeciation project (CGL2014-59886-JIN) of the Spanish Ministerio de Economia y Competitividad.

\section{Literature Cited}

Abbott, R. J., and M. F. Gomes. 1989. Population genetic structure and outcrossing rate of Arabidopsis thaliana (L) Heynh. Heredity 62:411-418.

Abdelaziz, M., M. Bakkali, J. M. Gómez, E. Olivieri, and F. Perfectti. 2019. Data from: Anther rubbing, a new mechanism that actively promotes selfing in plants. American Naturalist, Dryad Digital Repository, https://doi.org/10.5061/dryad.sd1hf16.

Ågren, J., and D. W. Schemske. 1993. Outcrossing rate and inbreeding depression in two annual monoecious herbs, Begonia hirsuta and B. semiovata. Evolution 47:125-135.

Angeloni, F., N. J. Ouborg, and R. Leimu. 2011. Meta-analysis on the association of population size and life history with inbreeding depression in plants. Biological Conservation 144:35-43.

Armbruster, W. S., S. A. Corbet, A. J. M. Vey, S.-J. Liu, and S.-Q. Huang 2014. In the right place at the right time: Parnassia resolves the herkogamy dilemma by accurate repositioning of stamens and stigmas. Annals of Botany 113:97-103.

Asker, S., and L. Jerling. 1992. Apomixis in plants. CRC, Boca Raton, FL.

Barrett, S. C. H. 2002. Evolution of sex: the evolution of plant sexual diversity. Nature Review Genetics 3:274-284.

Bomblies, K., L. Yant, R. A. Laitinen, S. T. Kim, J. D. Hollister, N. Warthmann, J. Fitz, and D. Weigel. 2010. Local-scale patterns of genetic variability, outcrossing, and spatial structure in natural stands of Arabidopsis thaliana. PLoS Genetics 6:e1000890.

Buttrose, M. S., W. Grant, and J. Lott. 1977. Reversible curvature of style branches of Hibiscus trionum L., a pollination mechanism. Australian Journal of Botany 25:567-570.

Cruden, R. W. 1977. Pollen-ovule ratios: a conservative indicator of breeding systems in flowering plants. Evolution 31:32-46.

Darwin, C. 1876. The effects of cross and self fertilisation in the vegetable kingdom. J. Murray, London.

. 1877. The various contrivances by which orchids are fertilised by insects. J. Murray, London.

Darwin, C., and F. Darwin. 1880. The power of movement in plants. J. Murray, London.

Edwards, W., and A. T. Moles. 2009. Re-contemplate an entangled bank: the power of movement in plants revisited. Botanical Journal of the Linnean Society 160:111-118. 
Feliner, G. N. 1991. Breeding systems and related floral traits in several Erysimum (Cruciferae). Canadian Journal of Botany 69:25152521.

Harder, L. D., and S. D. Johnson. 2009. Darwin's beautiful contrivances: evolutionary and functional evidence for floral adaptation. New Phytologist 183:530-545.

Husband, B. C., and D. W. Schemske. 1996. Evolution of the magnitude and timing of inbreeding depression in plants. Evolution 50:54-70.

Igic, B., and J. W. Busch. 2013. Is self-fertilization an evolutionary dead end? New Phytologist 198:386-397.

Jaffe, M. J., C. Gibson, and R. Biro. 1977. Physiological studies of mechanically stimulated motor responses of flower parts. I. Characterization of the thigmotropic stamens of Portulaca grandifolora Hook. Botanical Gazette 138:438-447.

Jarne, P., and D. Charlesworth. 1993. The evolution of the selfing rate in functionally hermaphrodite plants and animals. Annual Review of Ecology, Evolution, and Systematics 24:441-466.

Kalisz, S., D. W. Vogler, and K. M. Hanley. 2004. Context-dependent autonomous self-fertilization yields reproductive assurance and mixed mating. Nature 430:884-887.

Kamran-Disfani, A., and A. F. Agrawal. 2014. Selfing, adaptation and background selection in finite populations. Iournal of Evolutionary Biology 27:1360-1371.

Kearns, C. A., and D. W. Inouye. 1993. Techniques for pollination biologists. University Press of Colorado, Boulder.

Liu, K.-W., Z.-J. Liu, L. Huang, L.-Q. Li, L.-J. Chen, and G.-D. Tang. 2006. Pollination: self-fertilization strategy in an orchid. Nature 441:945-946.

Lloyd, D. G. 1979. Some reproductive factors affecting the selection of self-fertilization in plants. American Naturalist 113:67-79.

Lloyd, D. G., and D. J. Schoen. 1992. Self-and cross-fertilization in plants. I. Functional dimensions. International Journal of Plant Sciences 153:358-369.

Müller, H. 1883. The fertilisation of flowers. Macmillan, London.

Nagy, E. S., L. Strong, and L. F. Galloway. 1999. Contribution of delayed autonomous selfing to reproductive success in mountain laurel, Kalmia latifolia (Ericaceae). American Midland Naturalist Journal 142:39-46.

Nieto-Feliner, G. 1993. Erysimum, Hesperis, Alyssum. Pages 48-76 in S. Castroviejo, C. Gómez Campo, P. Montserrat, F. Muñoz Garmendia, and E. Rico. Flora iberica. Vol. IV. Cruciferae-Monotropaceae. Real Jardín Botánico, Madrid.

Ollerton, J., R. Winfree, and S. Tarrant. 2011. How many flowering plants are pollinated by animals? Oikos 120:321-326.
R Development Core Team. 2014. R: a language and environment for statistical computing. R Foundation for Statistical Computing, Vienna. http://www.R-project.org/.

Randle, A. M., R. B. Spigler, and S. Kalisz. 2018. Shifts to earlier selfing in sympatry may reduce costs of pollinator sharing. Evolution 72:1587-1599. doi:10.1111/evo.13522.

Ren, M. X., and J. Y. Tang. 2012. Up and down: stamen movements in Ruta graveolens (Rutaceae) enhance both outcrossing and delayed selfing. Annals of Botany 110:1017-1025.

Ruan, C. J., and J. A. T. da Silva. 2011. Adaptive significance of floral movement. Critical Reviews in Plant Sciences 30:293-328.

Sakai, S. 1995. Evolutionarily stable selfing rates of hermaphroditic plants with competing and delayed selfing modes with allocation to attractive structures. Evolution 49:557-564.

Schlindwein, C., and D. Wittmann. 1997. Stamen movements in flowers of Opuntia (Cactaceae) favour oligolectic pollinators. Plant Systematics and Evolution 204:179-193.

Scott, R. 1903. On the movements of the flowers of Sparmannia af ricana, and their demonstration by means of the kinematograph. Annals of Botany 17:761-777.

Sicard, A., and M. Lenhard. 2011. The selfing syndrome: a model for studying the genetic and evolutionary basis of morphological adaptation in plants. Annals of Botany 107:1433-1443.

Slotte, T., K. M. Hazzouri, J. A. Ågren, D. Koenig, F. Maumus, Y. Guo, K. Steige, et al. 2013. The Capsella rubella genome and the genomic consequences of rapid mating system evolution. Nature Genetics 45:831-835.

Takebayashi, N., and L. F. Delph. 2000. An association between a floral trait and inbreeding depression. Evolution 54:840-846.

van der Niet, T., R. Peakall, and S. D. Johnson. 2014. Pollinator-driven ecological speciation in plants: new evidence and future perspectives. Annals of Botany 113:199-212.

Webb, C. J., and D. G. Lloyd. 1986. The avoidance of interference between the presentation of pollen and stigmas in angiosperms II. Herkogamy. New Zealand Journal of Botany 24:163-178.

Whitehead, M. R., R. Lanfear, R. J. Mitchell, and J. D. Karron. 2018. Plant mating systems often vary widely among populations. Frontiers in Ecology and Evolution 6:38.

Wolkovich, E. M., and E. E. Cleland. 2011. The phenology of plant invasions: a community ecology perspective. Frontiers in Ecology and the Environment 9:287-294.

Editor: Daniel I. Bolnick 